\title{
Identification of chromosomal alpha-proteobacterial small RNAs by comparative genome analysis and detection in Sinorhizobium meliloti strain I 02 I
}

\author{
Vincent M Ulvé ${ }^{\dagger 1}$, Emeric W Sevin ${ }^{\dagger 1}$, Angélique Chéron ${ }^{1}$ and \\ Frédérique Barloy-Hubler*1,2
}

\begin{abstract}
Address: ${ }^{1}$ CNRS UMR6061 Génétique et Développement, Groupe Modèles Génétiques, Université de Rennes 1, IFR140 GFAS, Faculté de médecine, 2 avenue du Professeur Léon Bernard, CS 34317, 35043 Rennes Cedex, France and 2CNRS UMR6026 Interactions Cellulaires et Moléculaires, Groupe DUALS, Université de Rennes 1, IFR140 GFAS, Campus de Beaulieu, avenue du Général Leclerc, 35042 Rennes, France

Email: Vincent M Ulvé - vincent.ulve@rennes.inra.fr; Emeric W Sevin - emeric.sevin@univ-rennes1.fr; Angélique Chéron - acheron@univrennes1.fr; Frédérique Barloy-Hubler* - fhubler@univ-rennes1.fr

* Corresponding author †Equal contributors
\end{abstract}

Published: 19 December 2007

BMC Genomics 2007, 8:467 doi:10.1/86/147|-2164-8-467
Received: 5 June 2007

Accepted: 19 December 2007

This article is available from: http://www.biomedcentral.com/I47I-2|64/8/467

(c) 2007 Ulvé et al; licensee BioMed Central Ltd.

This is an Open Access article distributed under the terms of the Creative Commons Attribution License (http://creativecommons.org/licenses/by/2.0), which permits unrestricted use, distribution, and reproduction in any medium, provided the original work is properly cited.

\begin{abstract}
Background: Small untranslated RNAs (sRNAs) seem to be far more abundant than previously believed. The number of sRNAs confirmed in $E$. coli through various approaches is above 70 , with several hundred more sRNA candidate genes under biological validation. Although the total number of sRNAs in any one species is still unclear, their importance in cellular processes has been established. However, unlike protein genes, no simple feature enables the prediction of the location of the corresponding sequences in genomes. Several approaches, of variable usefulness, to identify genomic sequences encoding sRNA have been described in recent years.

Results: We used a combination of in silico comparative genomics and microarray-based transcriptional profiling. This approach to screening identified $\sim 60$ intergenic regions conserved between Sinorhizobium meliloti and related members of the alpha-proteobacteria sub-group 2 . Of these, 14 appear to correspond to novel non-coding sRNAs and three are putative peptide-coding or 5' UTR RNAs (ORF smaller than 100 aa). The expression of each of these new small RNA genes was confirmed by Northern blot hybridization.

Conclusion: Small non coding RNA (sra) genes can be found in the intergenic regions of alphaproteobacteria genomes. Some of these sra genes are only present in S. meliloti, sometimes in genomic islands; homologues of others are present in related genomes including those of the pathogens Brucella and Agrobacterium.
\end{abstract}

\section{Background}

Numerous DNA sequences giving rise to small non-coding RNAs (ncRNAs or sRNAs, ranging from size 50 to 250 $\mathrm{nt}$ for the vast majority of them) have been found in bacterial plasmids, phages, transposons and chromosomes.
Estimates of the number of ncRNA genes in E. coli range from 50 to several hundred [1,2]. The first ncRNAs were detected in the 1960s by chance, discovered by direct labelling as being associated with proteins on migration gels or identified after random mutations. The abundance 
of bacterial genome sequence data has allowed gene-finding computer programs to annotate a large number of prokaryote sequences. However, although de novo annotation programs successfully identify and map protein-coding genes, they are not designed to identify ncRNA genes. Recently, the intergenic regions (IGRs) of selected bacteria and yeast genomes were systematically searched for ncRNA genes. These computational screenings involved a combination of criteria, including large gaps between protein-coding genes $[3,4]$ even though in Sulfolobus solfataricus, 13 small RNAs (sRNAs) have been found encoded either within, or overlapping, annotated open reading frames [5]. Other criteria used are extended conservation between species $[2,4,6]$, orphan promoter or terminator sequences $[2,4,7]$, base-composition signatures $[8,9]$, and conserved secondary structures in deduced RNA sequences [10-13] even if not always significant [14]. Recently, ncRNA research algorithms have been developed including some or all of these criteria [15-18]. Supplementary in vivo experiments involving for example studies of expression patterns by Northern blotting or microarray testing are still essential to confirm that the sRNA candidate genes are indeed transcribed; such studies also provide information about temporal expression patterns, potential precursor forms and degradation products. In addition to in silico analysis, experimental in vivo RNomics were also developped (for example RACE and SELEX) [19-21].

ncRNAs are involved in a great variety of processes including chromosome replication and cell division ( $\operatorname{dicF}$ [22]), transcriptional regulation (6S RNA [23]), RNA processing (RNase P or $r n p B,[24]$ ), mRNA stability and translation (antisense sequences such as spot42 [25]), protein stability (tmRNA, [26]) and transport (4.5S or ffs, [27]), stress adaptation (for example oxyS [28]), transition from growth to stationary phase (dsrA, rprA [29,30]), quorum sensing and virulence ( $q r r[31])$, plasmid copy number control (RNAI and RNAIII [32,33]), carbon storage (csrBC [34]), and oligopeptide transport ( $g c v B$ [35]). Some provide housekeeping functions and others are regulators of stress gene expression, e.g. sRNAs modulating the bacterial cell surface by antisensing outer membrane protein (omp) genes (such as micF and $m i c C$, reviewed in $[36,37]$ ). In many cases, ncRNAs are associated with proteins that enhance their function (Hfq [38], SmpB [39]). Their mechanisms of action can be grouped into three main categories: antisense by base-pairing with another RNA/DNA molecule (oxyS), RNA structure mimicry (6S, tmRNA) and catalytic functions $(r n p B)$. These categories are not exclusive (some ncRNAs can be classified in more than one category). Also, not all mechanisms of action are known and it is likely that some ncRNAs act in ways that have not yet been described.
Sinorhizobium meliloti (formerly Rhizobium meliloti) is a common Gram-negative soil bacterium that lives symbiotically on the roots of certain genera of leguminous plants (including Medicago and Melilotus). The bacterium enters the root tissue through infection threads and forms nodules, inside which it converts atmospheric nitrogen into ammonia. In return, the plant provides an energy source for the bacteria. Excess nitrogen remains in the soil, potentially reducing the need for fertilisers. S. meliloti is one of the best known Rhizobia; it has been extensively studied by numerous groups worldwide and is readily amenable to genetic studies. Like many other members of the alpha-proteobacteria, this fast growing Rhizobium possesses a multipartite genome: a 3.65-Mb chromosome and two megaplasmids, pSymA (1.35 Mb) and pSymB $(1.68 \mathrm{Mb})$ [40]. Its genome shares various fundamental similarities with those of some other symbiotic bacteria and various plant (Agrobacterium) and animal pathogens (Bartonella, Brucella). As for most sequenced prokaryotic genomes, the annotation of the $S$. meliloti genome has led to the prediction of protein-coding genes but yielded very little information about non-coding RNA genes. When the genome sequence of the $S$. meliloti strain 1021 was completed [40], its RNome was only composed of three identical rRNA operons, 54 tRNAs (53 decoding the standard 20 aa and one selenocysteine tRNA), and a single annotated ncRNA, ssrA (tmRNA or smc04478). The characterisation and expression patterns of this RNA gene were recently published [41]. Two other ncRNAs are described in dedicated databases $[27,42]$ one matching $\operatorname{rnp} B$, the RNA component of the ubiquitous RNAse P ribonucleoprotein enzyme, and the other ffs (4.5S RNA), the RNA constituent of the signal recognition particle (SRP). Recent work by MacLellan with S. meliloti strain 1021 [43] and Izquierdo with strain GR4 [44] also describes ctRNAs (counter-transcribed-RNA) involved in plasmid incompatibility. In addition, 5' untranslated regions (UTR) of mRNAs that act as "riboswitches" have also been predicted in $S$. meliloti. Those cited by the Rfam database $[45,46]$ sense concentrations of vitamins B2 (RFN, upstream from ribH2) and B12 (cobalamin, upstream from $c o b P, s m b 20056, s m c 00982$, smc00166 and between smb20555-smb20556), of thiamine (THI, in 5' of thiD, thiC and $s m c 03869$ ) and of glycine ( $5^{\prime}$ end of $g c v T$ ). Corbino $e t$ al. [47] also describe riboswitches for methionine (SAM, in front of metA and metZ) and serine (serC), as well as elements upstream of suhB, smc02983 (speF) and smc03839 $(y b h L)$. No lysine, leucine, threonine or tryptophan riboswitches have been predicted in S. meliloti or in related alpha-proteobacteria. Finally, a repression of heat shock gene expression (ROSE) element is also annotated in the RFAM database, in the $5^{\prime}$ translated region of smb21295 (ibpA-like). 
The purpose of this study was to discover unidentified small RNA genes in the chromosome of $S$. meliloti and related alpha-proteobacteria. We used computational comparative genomic prediction of sRNA gene candidates combined with expression profiling using dedicated microarrays, followed by Northern hybridization. This approach revealed 17 previously unidentified sRNAs, eight of which are widely conserved in the alpha-proteobacteria phylum. These analyses suggest that, like other free-living bacteria, alpha-proteobacteria encode numerous sRNAs, although their number and their nature may differ between species.

\section{Results and discussion}

\section{Profile of small RNAs in S. meliloti}

Staining of total RNA from bacteria resolved on gels reveals abundant sRNAs [48-52]. We used this method to analyse S. meliloti small RNA (<400 nt: Figure 1A). Four intense bands were detected, three of which correspond to the sizes predicted for 5S RNA (band 5), 4.5S RNA (band $2)$, and the 5 ' end of tmRNA (band 4, [41]). Band $6(\approx 70$ nt) corresponds to a length and migration profile compatible with tRNAs. No RNAs migrating faster than $70 \mathrm{nt}$ were detected. Two less intense bands (1 and 3 ) were observed and were compatible with sizes predicted for rnpB RNA and for the 3 ' end of tmRNA [41]. Northern blotting confirmed the identity of each of these bands (Figure 1B). Surprisingly, no additional RNAs were visualized with either RNA extraction method (Trizol ${ }^{\mathrm{TM}}$ or Qiagen $^{\mathrm{TM}}$, not shown) or stress (see conditions in Material and Methods section, data not shown). This experiment indicated that small RNAS do not constitute an abundant class of RNAs in S. meliloti, in contrast to what has been observed in marine Cyanobacteria and in Staphylococcus aureus [50-52]. As a consequence, we could not employ direct elution and sequencing to identify new sRNAs [53] in S. meliloti. We thus used computational prediction to identify candidates for further testing.

\section{Known sRNAs of S. meliloti: distinguishable biases?}

ncRNAs in AT-rich hyperthermophiles can be located on the basis of local variations in genomic base composition $[10,11]$. Although the $S$. meliloti chromosome is GC-rich (62.7\%), we scanned the regions containing tmRNA, rnpB and $f f s$ (Figure 2) for base composition signals. Unlike ATrich genomes, no difference was observed between sRNA and background genomic sequences (Table 1). BLAST alignments of the three sRNAs against all sequenced bacteria revealed significant similarities with sequences from the alpha-2 subgroup of the class Proteobacteria. However maximum likelihood trees (see Additional file 1) showed that most identical sequences were from different genomes ( $R$. etli and leguminosarum for ffs and tmRNA; Mezorhizobium for $r n p B$ ). To conclude, no apparent dominant bias was observed for the three known $S$. meliloti

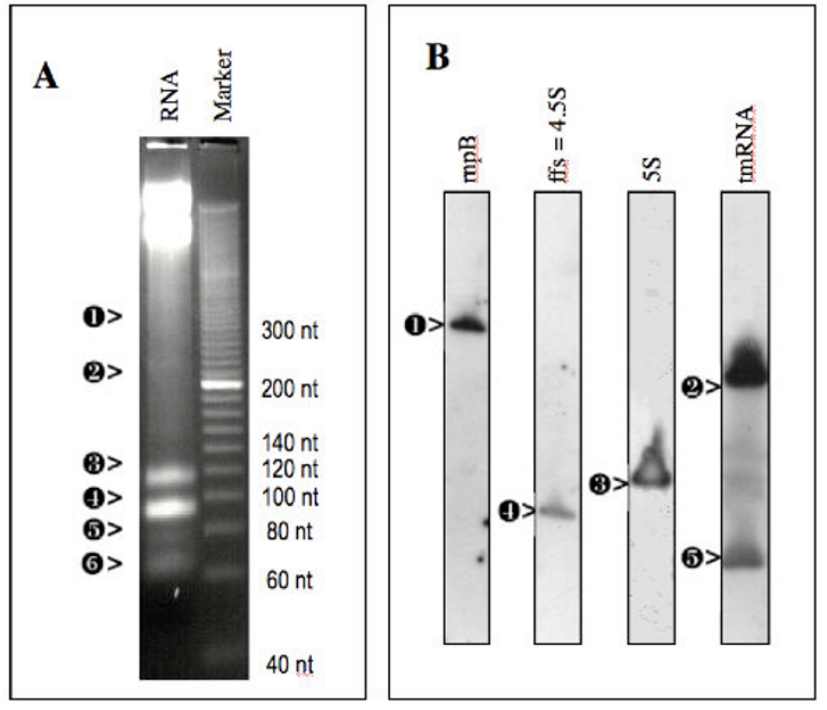

\section{Figure I}

Identification of small "known" RNAs in the $S$.

meliloti chromosome. A: Migration of $10 \mu \mathrm{g}$ of S. meliloti total RNA in a $2.5 \%$ high-resolution agarose gel (Sigma) stained with ethidium bromide. B: $5 \mu \mathrm{g}$ of total RNA from $S$. meliloti strain 1021 was analyzed by Northern blotting hybridization with specific oligonucleotides [see Additional file 8]; the molecular sizes were calculated in nucleotides $(n t):$ ( $>$ $\operatorname{rnpB}(372 \mathrm{nt}), 2>\operatorname{tmRNA} 3^{\prime}$ end (204 nt), $3>5 \mathrm{~S}$ ( 120 $n t), 4$ > $4.5 \mathrm{~S}$ (95 nt), and $\mathbf{5}>$ tmRNA 5 ' end (82 nt) [39]. Band $\mathbf{6}>$ was not hybridized but its size is consistent with it being a tRNA. Exposure times were optimized for each panel and signal intensity does not indicate relative abundance of ncRNAs.

ncRNAs, except primary sequence conservation in IGRs of related alpha-proteobacteria genomes (especially subgroup-2).

\section{Selection of sRNA candidate genes in the S. meliloti chromosome}

Most bacterial sRNA searches were conducted using the $E$. coli genome as a reference, so we first compiled the sRNAs available in the Rfam database for that organism (strain $\mathrm{K} 12$, riboswitch/cis-regulatory genes excluded) to try to identify sRNA orthologs using BLAST alignments (e-value $<1)$ against the complete S. meliloti chromosome sequence. No significant similarities were detected except for $4.5 S$ and $r n p B$ (see Additional file 2). ssrA (tmRNA) was not detected, presumably because the $S$. meliloti tmRNA is in a two-piece "permuted" form [41]. Surprisingly, the "ubiquitous" ssrS (6S RNA) was not detected either. Similar analysis with Bacillus and Pseudomonas sRNAs [RFAM] gave no further hits. This first approach 
confirmed a key point: most sRNAs cannot be detected by inter-phylum primary sequence identity.

RNA-specific tools described in the literature were then assessed. However, most rely on preliminary structural knowledge, knowledge which is poor for this phylum. Thus only a subset of these tools was tested: those reported to be able to detect new sRNA gene candidates in prokaryotic species. ISI (Intergenic Sequence Inspector, [54]) relies on inappropriate filters (in particular GC\%), and was far too sensitive if the filters were disabled (close to 300 candidates). The use of QRNA [7] requires preliminary alignments. We tested it by aligning the 61 sRNAs annotated in the E. coli (K12) genome against $S$. meliloti's chromosome, but only $4.5 \mathrm{~S}$ and $r n p B$ were predicted by this tool. Finally, we assessed sRNApredict2 [18], which

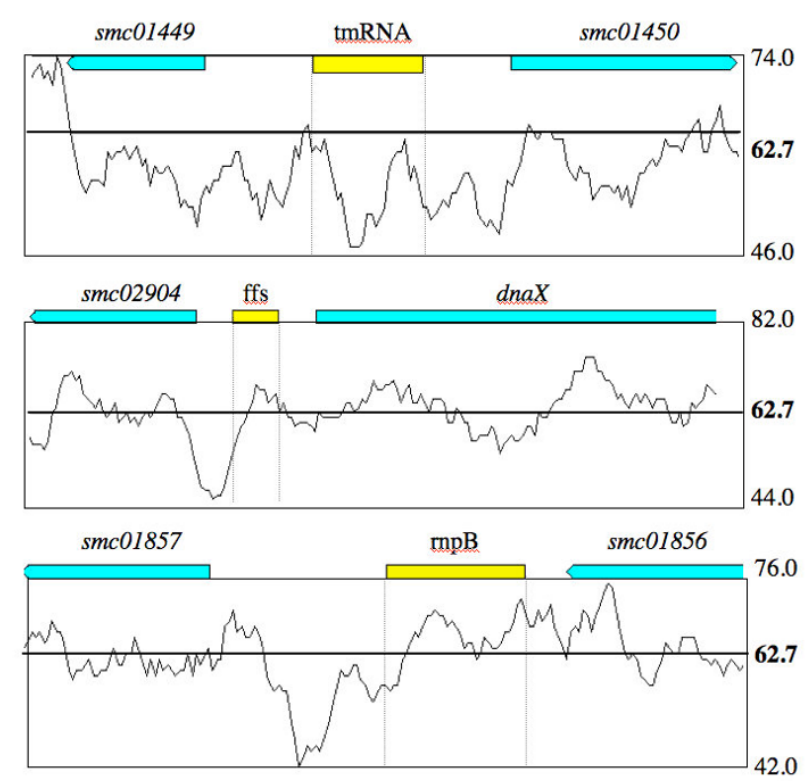

Figure 2

Nucleotide bias analyses of known S. meliloti RNAs. Local variations of GC content (\%) with a window size of 100 bp, in S. meliloti genomic regions around tmRNA, ffs and rnpB. The $y$-axis represents the minimal, maximal and mean values of the percentage of GC.

Table I: Selected features of "known" ncRNAs of S. meliloti combines commonly sRNA-associated genetic features; it was used to search the $S$. meliloti chromosome IGRs for sRNAs, by comparison with A. tumefaciens and R. etli. As shown in the output tables (see Additional file 3), 13 sRNAs were predicted, seven being common to the two genomes compared. However, a detailed analysis of each candidate revealed that only one (pred1) was likely to correspond to a genuine small RNA gene whereas the others are almost certainly $5^{\prime}$ UTRs (in view of the small distances and nature of the surrounding genes) or repeated elements (RIME, Sm- $[55,56])$.

We ended up selecting for further analysis: the IGRs containing the origin of replication oriC (as a negative control) and the tmRNA, $\operatorname{mpB}$ and 4.5S RNA genes; 22 IGRs longer than $450 \mathrm{nt}$; 13 IGRs showing short sequence identity in alpha-proteobacteria (see Additional file 10); and 28 IGRs selected using the Artemis Comparison Tool (ACT) with related genomes (see Additional file 11). Indeed, the sequence identities marked by the ACT were mostly confined to actual open reading frames (ORFs), even between two close chromosomes ( $S$. meliloti and A. tumefaciens). Although hits in intergenic regions were extremely rare (less than 40 ), all three $S$. meliloti known sRNAs ( $\operatorname{tmRNA}, 4.5 S$ and $r m p B)$ were included in these hits: we thus concluded similar ACT-visualized IGRs represented good sRNA gene candidates. Among these IGRs, those containing large repeats (Sm-1 to Sm-5) or RIMEs were however excluded, as were IGRs smaller than $50 \mathrm{nt}$ (to avoid inclusion of 5' or 3' UTR elements).

This selection accounted for 67 candidate IGRs (see Additional file 4), which throughout this paper shall be referred to as sra, followed by a number corresponding to their order of apparition on the chromosome (starting from oriC).

\section{Detection of expression using microarrays and Northern dotting}

Microarray hybridization was the first method used to test for transcription of the sRNA candidates; an IGR-dedicated array was used (see Materials and Methods). The initial goal of the time-course microarray experiments was to detect ncRNA gene transcripts in various conditions. We first monitored gene expression over time during growth

\begin{tabular}{lllllllll}
\hline Name & Strand & \% IGR & A\% & C & G\% & T\% & GC\% & GC-AT skew \\
\hline 4.5S = ffs & +/Leading & 34.5 & 18.2 & 33.7 & 33.7 & 14.4 & 67.4 & $0.00-11.76$ \\
tmRNA & +/Lagging & 45.1 & 24.3 & 28.0 & 28.4 & 19.3 & 56.4 & $0.55-11.43$ \\
rnpB & -/Leading & 44.6 & 22.1 & 30.5 & 36.6 & 10.8 & 67.1 & $9.09-33.85$ \\
\hline
\end{tabular}


in minimal (MV) and rich (LB) media. The average $\log _{2}$ SNR of the three known ncRNAs (tmRNA, $r n p B$ and 4.5S) and the ribosomal RNA 5S (included as a control) was very low (0.49) in MV medium, but was higher (4.13) in LB medium (see Additional file 5). We applied various stresses, as described in Materials and Methods, but detected no specific induction (not shown). We therefore used LB medium for expression analyses and the results are expressed as a heat map (Figure 3). We also checked the expression of all of the candidates by Northern dot blotting. Twenty-five candidates were found to give a strong hybridization signal (including $r n p B$ and 4.5S RNA genes) and nine gave weak but detectable signals. Among the dot blot-"positive" IGRs, ten did not show significant expression on microarrays (Fig. 3, group B1), perhaps due to insufficient fluorescent labelling (e.g. the RNA was too small or labelling was hampered by secondary folding). Twenty-three IGRs gave no transcription signal either in Northern dot blots or in microarrays (Fig. 3, group B2). These included sra01, which corresponds to the S. meliloti origin of replication (oriC or smc04880) and was used as an internal negative control. Indeed, various methods (including QPCR and blotting) have been used to demonstrate that there is no transcription at this site (not shown). Lastly, 11 IGRs giving a transcription signal on microarrays were not confirmed by Northern dot blotting; in these cases the signal may have originated from surrounding coding genes.

Small RNA transcripts detected by Northern hybridization Northern blotting was used to detect sRNAs. The same probes as for Northern dots were used but after hybridization of newly purified RNA from fresh cultures. For some candidates, probes were redrawn to target areas common to all considered subgroup-2 alpha-proteobacteria. sra15 was discarded because it appears to correspond to a pseudo phe-tRNA gene (not shown). This locus is possibly a vestige or a target of DNA insertion; indeed, a 500-kb symbiosis island has been shown to integrate into a phetRNA in the M. loti chromosome [57].

Four sRNA candidates (sra51, sra37, sra47, sra59) gave large transcripts ( 1000 nt, not shown), inferred to be part of adjacent ORFs for three reasons: (i) they were larger than the intergenic region; (ii) they were large enough to encompass one of the flanking coding genes; and (iii) the strand detected corresponded to the orientation of at least one of the flanking genes. We did not pursue investigations to determine whether these $5^{\prime} / 3^{\prime}$ UTRs encompass cis-regulatory RNA structures.

The signals detected for sra 48 , sra58 and sra62 were very strong and composed of multiple bands (data not shown). For $\operatorname{sra} 48$ and sra58, the explanation is sequencespecific hybridization of the probe to various transcripts due to small imperfect DNA repeats (sm-2 fragment in the case of $\mathrm{sra} 58$ and a previously undescribed repeat in $\mathrm{sra} 48$, data not shown). The sra62 candidate corresponds to a repeated region that coincides with the fixT loci, present in three copies in the genome of $S$. meliloti [40]. In the two first copies, fixT genes (fixT1 and fixT2) are co-located with fixK genes (fixK1 and fixK2). The third copy region of fixT gene (fixT3) encompasses sra62, which corresponds to a fixK3 pseudogene (not shown).

However, it cannot be concluded that the 23 candidates (group B2, Figure 3) for which no transcript was detected by microarray or Northern blot experiments correspond to false predictions: some of them may possibly be true sRNAs, but which are poorly or not expressed in the conditions tested.

\section{Analysis of the 17 newly identified small RNAs}

We further investigated the 17 sRNA candidates that yielded signals with a suitable size in Northern blots (<300 nt, Figure 4A). We excluded (Table 2) sra10, that contains a possible 101 amino acid ORF and sra29, which is a probable leader for $r p s F$ ( $\mathrm{S} 6$ ribosomal protein gene) $[58,59]$; we also excluded sra 24 that may encode a short peptide (38 aa long) rather rich in cysteine (10\%). The 23 first aa (MALFFKPHCFLSLYCCLLSQRG...) correspond to a predicted transmembrane segment whereas $30 \%$ of the 14 other residues are positively charged amino acids. This biochemical configuration is found in small molecular peptide ion channels, such as defensins, involved in hostdefences.

Of the 14 remaining RNAs, six correspond to S. melilotispecific sRNAs (called orphan sRNAs, Table 3). All except sra61 lie within a genomic island [60] (sra14 in Smc19T; sra11, sra12a and sra12b in Smc21T; sra66 maps at the 5' end of Sme80s, just downstream from the insertion tRNA ${ }^{\text {ser }}$ gene smc03779). All these sRNAs are absent from Agrobacterium and other Rhizobium species, consistent with the absence of the three genomic islands from these related genomes. The "coding potential" of sra11, sra12a, $s r a 12 b$ and sra 14 was assessed and only sra66 could translate a small non-conserved 16 aa peptide. There may be a relationship between their biological functions and their presence in genomic islands as bacterial islands are often related to eukaryotic host cell colonization (virulence or symbiosis). Indeed bacterial sRNAs were recently detected in the pathogenicity island of Staphylococcus [51] and in Salmonella (InvR [36]). Multiple 5' and 3' RACE mapping of these candidates was unsuccessful, possibly due to insufficient cDNA or because they are too small for satisfactory cloning. With no available orthologous sequences, determination of extremities through alignment and structure prediction based on covariations are not possible. The functions of these new non-coding genes are thus 


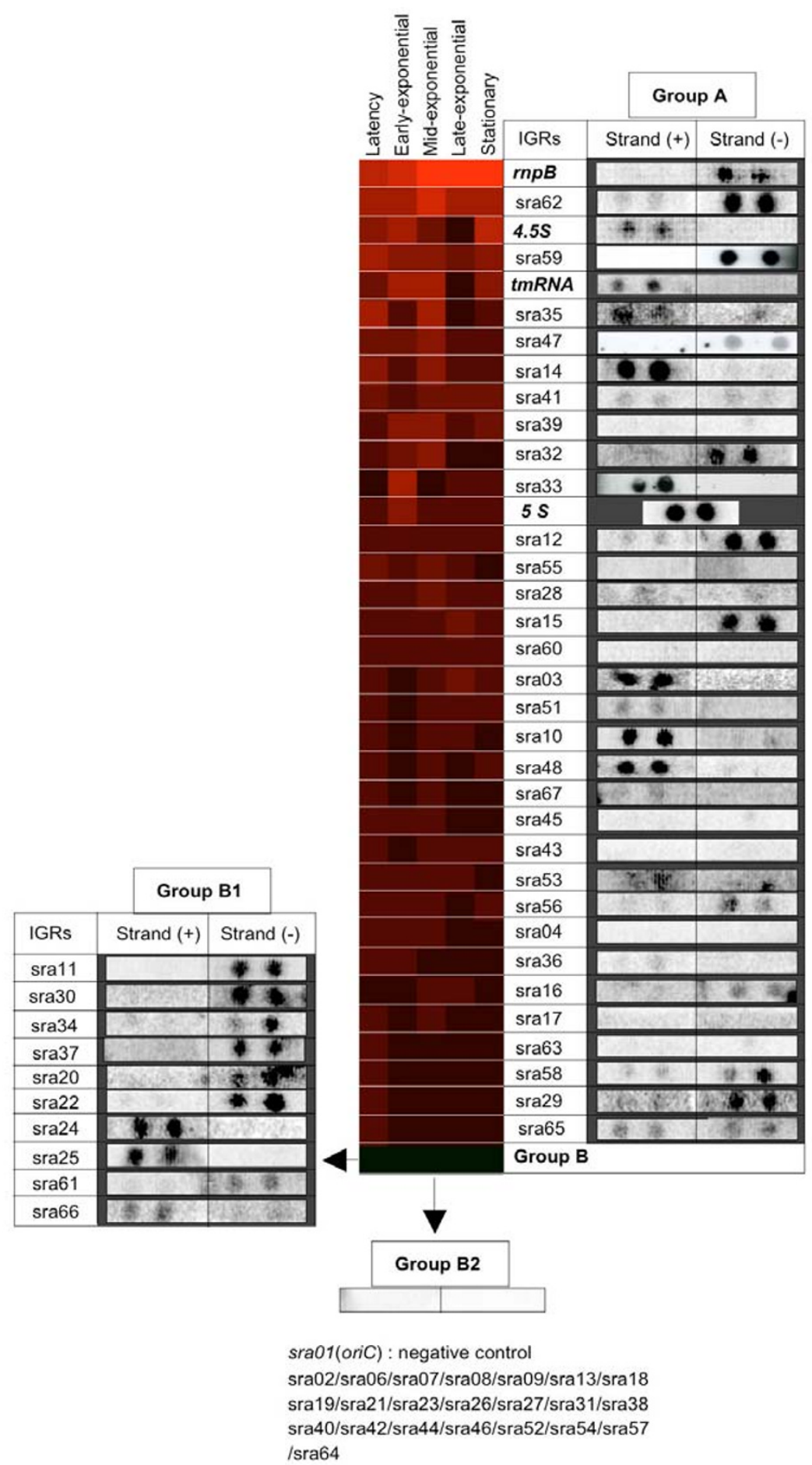

Figure 3

Heat map and Northern dot expression analysis of $\mathbf{S}$. meliloti sra genes. Heat map visualizing the expression values for each sra gene at various stages of growth (in LB medium). Signal intensities are indicated as signal-to-noise SNR values (log2 scale), represented by a red panel. The position of each sra gene in the heat map is determined by its intensity. For the complementary Northern dot analysis, $10 \mu \mathrm{g}$ of RNA, isolated from the most favourable expression condition, was spotted (in duplicate) onto a nylon membrane and hybridized with a radiolabelled specific probe [see Additional file 8]. 
A

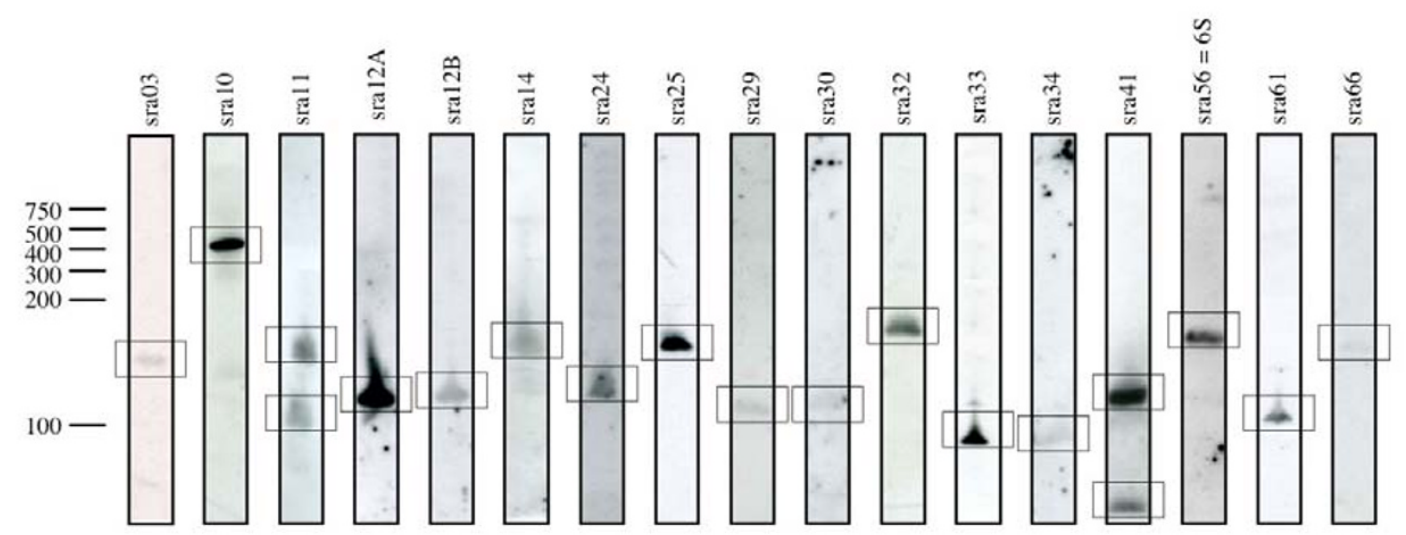

B

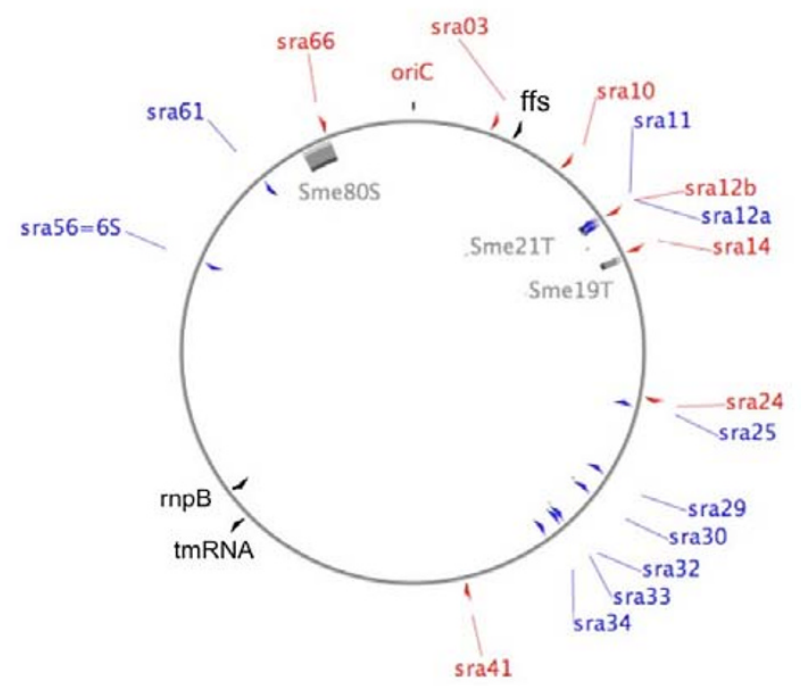

\section{Figure 4}

Detection and location of chromosomal S. meliloti sRNAs. A. Total RNA was extracted from cultures grown in LB (mid-exponential phase). Northern blots were hybridized with biotinylated DNA oligonucleotide probes [see Additional file 8] and exposed for various times (therefore the intensities of the signals do not correspond to the relative abundance of each sRNA). The positions of RNA size standards are shown on the left. B. Distribution of the sra genes along the S. meliloti chromosome. The origin of replication (oriC $=$ sraOI) and positions of tmRNA, rnpB and $4.5 \mathrm{~S}$ are also indicated. Blue and red arrows represent genes on the reverse or forward strands, respectively. Genomic islands are indicated with grey boxes (Sme2IT, Sme 19T and Sme80S).

unknown. However, many small RNAs in bacteria act as post-transcritptional regulators via base-pairing action, so we used TargetRNA [61] to assess their capacity to act as antisense RNAs. No significant putative target was found for sra11, sra12a, sra14 or sra61, but sra12b and sra66 match with mRNA targets (see Additional file 12). One interesting TargetRNA prediction was the interaction between sra66 and a tolR-exbD-like gene (smc03957). TolR-ExbD proteins are membrane-bound transport proteins essential for ferric ion uptake in bacteria [62], and 
Table 2: Features and annotations of the 3 new small RNAs of S. meliloti potentially encoding proteins and peptides

\begin{tabular}{|c|c|c|c|}
\hline & sralo & sra24 & sra29 \\
\hline Flanking genes & rpsT-dnaA & Y00I25-027 & rpsF-Y00569 \\
\hline Orientation & $>>>$ & $<>>$ & $<<>$ \\
\hline Estimated size(s) (nt) & 383 & 104 & 110 \\
\hline R. etli CFN 42 & • & - & $\cdot$ \\
\hline R. leguminosarum & • & - & - \\
\hline A. tumefaciens $\mathrm{C} 58 / \mathrm{C}$ & • & - & • \\
\hline A. tumefaciens C58/W & • & - & • \\
\hline M. loti MAFF & - & - & - \\
\hline B. suis & - & - & • \\
\hline B. melitensis & - & - & • \\
\hline B. abortus & - & - & • \\
\hline Possible functions & ORF & Peptide & 5' UTR \\
\hline
\end{tabular}

Table 3: Features and annotations of the 6 new orphan (S. meliloti-specific) sRNAs of S. meliloti

\begin{tabular}{|c|c|c|c|c|c|c|}
\hline & srall & sral2a & sral2b & sral4 & sra6I & sra66 \\
\hline Flanking genes & Y0220I-2189 & Y02I5I-50 & Y02I5I-50 & Y02287-2205 & Y03।08-3107 & Y003769-79 \\
\hline Orientation & $><<$ & $<<>$ & $<>>$ & $<><$ & $><<$ & $<><$ \\
\hline $\begin{array}{l}\text { Estimated size(s) } \\
\text { (nt) }\end{array}$ & 150 and 90 & 104 & 104 & 120 & 89 & 144 \\
\hline Possible functions & UD & UD & Antisense & UD & UD & Antisense \\
\hline
\end{tabular}

UD : undetermined

small RNAs modulating the free intracellular iron pool have indeed been identified in other bacteria (e.g $R y h B$, [63]).

In E. coli, sRNA genes were considered to be conserved if the alignment had an E-value lower than 0.001 [64]. On this basis, the sequences of the eight remaining expressed $S$. meliloti sra genes are highly conserved in related alphaproteobacteria (e-value $<10^{-10}$; Table 4). sra56 is even an analog of Escherichia coli's 6S RNA (SsrS) that has recently been corroborated by RFAM. sra56 may thus be considered as a fortuitous positive control, validating our experimental approach. All these conserved sra genes we describe were then subjected to transcriptional element analysis, structure prediction using covariation, and potential mRNA target prediction.

\section{Genomic synteny for alpha-proteobacteria sra genes}

S. meliloti chromosomal sRNA-encoding genes have a slight distribution preference, $70 \%$ of them being on the left replicore, but no preference was observed concerning the leading or the lagging strand (Figure 4B). The conservation of gene adjacency (synteny) may be associated with functional relationships (e.g. gcvB and $s s r A$ are functionally associated to their conserved adjacent genes, respectively $g c v A$ and $\operatorname{smp} B)[35,65]$. Therefore, we assessed the conservation of neighbouring genes for the eleven alphaproteobacterial $s r a$, including $t m R N A, r n p B$ and $4.5 S$ (see Additional files 10 and 11). We found only three (4.5S, tmRNA and sra41) where both flanking genes were conserved and four with one conserved flanking gene (including $r n p B$ ). Three display no synteny (including sra56 = $6 S$ ). However, our observations suggest that in alpha-proteobacteria, functional association between sRNAs and conserved adjacent genes is uncertain, as even $s m p B$ is not linked to tmRNA (separated by $1,1 \mathrm{Mb}$ ).

\section{Conserved sra gene transcriptional signals}

The computational identification of promoter sequences is difficult because signals are weak [4]. Consensus binding sites have been proposed for the S. meliloti $\sigma^{70}$ and $\sigma^{54}$ dependent promoters (CTTAGAC-n17-CTATAT [66] and TGGCACG-n4-TTGCW [67], respectively). Using relaxed regular expressions (i.e. pattern matching), we scanned the 5' UTR region of each sra gene to detect any such consensus (max. 4 mismatches). In the same way than for the orphan candidates, the end-mapping experiments remained unsuccessful for all new candidates but sra32 (5' end-AAACAGGCAGGAA and 3 ' end-CTTGTTTTTTT), thus the exact sites of the extremities of the sra genes are unknown. However, sequence alignment between several alpha-proteobacteria was informative. As for ORFS, no 
Table 4: Features and annotations of the 8 new Alpha-proteobacterial sRNAs of S. meliloti

\begin{tabular}{|c|c|c|c|c|c|c|c|c|}
\hline & sra03 & sra25 & sra30 & sra32 & sra33 & sra34 & sra4l & sra56 \\
\hline $\begin{array}{l}\text { Flanking } \\
\text { genes }\end{array}$ & polA-Y0285I & Y00034-96 & Y0I755-aspS & Y01933-proS & celR2-rpmG & tufB-Y0I 325 & Y0I $226-25$ & Y03975-76 \\
\hline Orientation & $<<>$ & $>><$ & $<<>$ & $<<>$ & $>><$ & $><>$ & $<<>$ & $><<$ \\
\hline $\begin{array}{l}\text { Estimated } \\
\text { size(s) (nt) }\end{array}$ & 120 & 144 & 104 & 133 & 76 & 76 & $106 \& 68$ & 127 \\
\hline R. etli CFN 42 & • & • & - & • & • & - & • & • \\
\hline $\begin{array}{c}R . \\
\text { leguminosarum }\end{array}$ & • & • & - & • & - & - & • & • \\
\hline $\begin{array}{l}\text { A. tumefaciens } \\
\text { C58/C }\end{array}$ & • & • & - & • & • & - & • & • \\
\hline $\begin{array}{l}\text { A. tumefaciens } \\
\text { C58/W }\end{array}$ & - & - & - & - & - & - & - & - \\
\hline M. loti MAFF & - & - & - & $\bullet$ & $\bullet$ & - & $\bullet$ & • \\
\hline B. suis & - & - & - & - & - & - & - & • \\
\hline B. melitensis & - & - & - & - & - & - & - & • \\
\hline B. abortus & - & - & - & - & - & - & - & • \\
\hline $\begin{array}{l}\text { Possible } \\
\text { functions }\end{array}$ & UD & UD & UD & Antisense & Antisense & Antisense & Antisense & $6 \mathrm{~S}$ \\
\hline
\end{tabular}

UD : undetermined

Dot $(\bullet)$ represents e-values $>10 \mathrm{e}^{-4}$

significant nucleotide identities were apparent in the $5^{\prime}$ and 3 ' regions (not shown). Thus, the start and stop of the alignment and the sizes deduced from electrophoretic motility were used to define the ends of each sra gene. We only detected consensus $\sigma^{70}$-promoters in the ubiquitous ncRNAs (ffs, tmRNA, $m p \phi B$ and $6 S$ ) and the 5'-UTR mapped region of sra32 (Table 5). Even with a larger spacer between the -35 and -10 boxes (17 to 20 ), no consensus sequence was detected in the other sra genes. Similarly, only the ffs $5^{\prime}$-UTR matches a possible $\sigma^{54}$ binding site. However, $S$. meliloti contains a large number of predicted sigma-factors (ca. 16), it is therefore possible that sra genes are dependent on them. Unfortunately, Melinabased [68] motif extraction from the promoter regions of these genes was inconclusive and did not show any consensus.

We also looked for potential classical L-shaped terminators (stable stem-loops followed by U-stretches) at the alignment-deduced 3' end of each sra. As most terminators in GC-rich bacteria have no long consecutive Ustretches [69], we also looked for I-shaped (stable stemloop with no U-stretch) and V-shaped (two consecutive hairpins [69]) terminators (Table 6). Terminator structures could be predicted for all conserved sra genes, except sra30 and sra34, for which the alignments are too short for the ends to be accurately mapped. All three shapes were found, I-shapes being the most common. This supports the proposal that "orphan" terminators in IGRs may indicate the presence of an sra gene, although because of the high GC content of the S. meliloti genome, stable stemloops are frequent and consequently not very informative.

\section{Conserved sra genes predicted structure and mRNA targets}

The structures of non-coding RNAs are important for their function. Consequently, we made a conserved secondary structure prediction for all alpha-proteobacteria sra genes (except sra30 and sra34 because of too short alignments).

We first compared the 4.5S and 6S Alifold [70,71] and RNAz [72], outputs with the equivalent RFAM structure (Additional file 13). The two tools give different structures for $4.5 \mathrm{~S}$, the Alifold prediction being closer to that of RFAM than the RNAz prediction. However, bulge A, the minimal site required for binding to EF-G [73], is similarly folded in the three models. The three predicted structures of sra56 (6S) are similar, 6S being folded as a largely double-stranded RNA with a single-stranded central bulge. However, the 3' side of the central bulge can form a stable stem-loop in alpha-proteobacteria, as previously described [74].

The predicted structure of sra03 is well-conserved, composed of three long hairpins: the central one, ending with a $15 \mathrm{nt}$ loop, is strictly conserved, and the 3 ' and 5' stemloop structures present co-varying nucleotides. Analogous design (three stem-loops) was found for the E. coli sRNAs drsA, micC and $q r r$ [46]. No significant target mRNA was found using the full RNA but the 15-nt loop presents complementarity with the 5'-UTR of the smc03977-smc03976 operon (not shown). These two genes have paralogs, mostly in alpha-proteobacteria genomes. The function of Smc03977 is unknown but Smc03976 belongs to the ZapA cell division family of proteins [75]. ZapA binds the 
Table 5: Promoter detection in conserved S. meliloti sra genes

\begin{tabular}{|c|c|c|}
\hline & б70-dependent [68] & б54-dependent [68] \\
\hline $\operatorname{tmRNA}$ & $\begin{array}{l}\text { tTTtct-n I7-TATATg } \\
{[4 I]}\end{array}$ & - \\
\hline sra05-ffs & CTTgca-n I7-cgATAT & tTGGCtt-n4-TTGCT \\
\hline sra50-rnpB & $\begin{array}{l}\text { CTctGgC-n I7- } \\
\text { tTtaAT }\end{array}$ & - \\
\hline sra56-6S & $\begin{array}{l}\text { CTgGtG-n I7- } \\
\text { CTATAT }\end{array}$ & - \\
\hline sra03 & - & - \\
\hline $\operatorname{sra25}$ & - & - \\
\hline sra32 & $\begin{array}{l}\text { gaTGAC-n l7- } \\
\text { CTA.AT }\end{array}$ & - \\
\hline sra33 & - & - \\
\hline sra4l & - & - \\
\hline
\end{tabular}

ftsZ cell division gene, which has been reported to undergo antisense inhibition in E. coli [22], so sra03 is possibly implicated in cell division regulation.

sra25 was only identified in Rhizobia (meliloti, etli and leguminosarum), however with remarkable primary sequence identity. Its predicted secondary structure is also highly conserved, composed of a long stem with one central bulge and a small hairpin. The 3 ' end structure was predicted to act as a stabilization terminator. A possible pairing with the $5^{\prime}$ UTR of a gene encoding a putative membrane protease protein (Smc04020) was proposed by TargetRNA, although with low significance ( $p$-value > $10^{-3}$ ). This protein resembles the E. coli HflKC protein, known to interact with the cell division protease FtsH [76]. As for sra03, we propose that sra25 may have a role in the S. meliloti cell cycle.

Only Alifold proposed a consensus structure for sra33: it resembles other short bacterial sRNAs including RyeE [46]. Predictions for sra33 showed strong pairing ability with the 5' ends of smc00899 and of rkpJ. The first gene is organized in an operon structure with smc00900 (encoding a PilT-like toxin), defining a post-segregational killing toxin-antitoxin (TA) system. This type of mechanism, involving sRNAs in the inhibition of TA systems, has been extensively described in E. coli [77]. Finding such a mechanism in $S$. meliloti is interesting as we recently detected approximately 53 TA loci (accounting for 95 genes) in the complete genome sequence [78].

sra32 is the only small RNA predicted both by sRNApredict2 and ACT analysis. For this gene, hybridization was tested by Northern blot and a signal was obtained for two of the most distant members: A. tumefaciens (140 nt) and R. elti (132 nt) (Figure 5A and 5B). The secondary structures of sra32 were predicted by both Alifold and RNAz; 59\% of the nucleotides can pair in seven
Table 6: Terminator prediction for S. meliloti sra genes

\begin{tabular}{|c|c|c|}
\hline & $\begin{array}{l}\text { Sequences or } \\
\text { references }\end{array}$ & Shape type [69] \\
\hline $\operatorname{tmRNA}$ & $\begin{array}{l}\text { P6 and P7 stem-loops } \\
{[4 I]}\end{array}$ & V-shaped \\
\hline sra05-ffs & $\begin{array}{l}\text { GGCACGG-n4- } \\
\text { TCGTGCC-agcct }\end{array}$ & I-shaped \\
\hline sra50-rnpB & $\begin{array}{l}\text { GTTTCGTCTC-n4- } \\
\text { GAGGCGGAGC- } \\
\text { catac }\end{array}$ & I-shaped \\
\hline sra56-6S & $\begin{array}{l}\text { CGGTC-n6- } \\
\text { GATCG-cactt }\end{array}$ & I-shaped \\
\hline sra03 & $\begin{array}{l}\text { CGGCATT-n5- } \\
\text { AGTGCCG-ctcga }\end{array}$ & I-shaped \\
\hline $\operatorname{sra25}$ & $\begin{array}{l}\text { GGGCCGCC-n3- } \\
\text { GGGCGGCCC-tttt }\end{array}$ & L-shaped \\
\hline sra32 & TB8 (cf figure 5) & I-shaped \\
\hline sra33 & $\begin{array}{l}\mathrm{TG}_{4} \text { TCGG-n4- } \\
\text { CTGGCCTCG et } \\
\text { T2GCGG-n I0- } \\
\text { CTGCAA- }\end{array}$ & V-shaped \\
\hline sra4l & $\begin{array}{l}\text { AGGGCCcAAG-n5- } \\
\text { CTTGtGGCCCT- } \\
\text { cttttttt }\end{array}$ & L-shaped \\
\hline
\end{tabular}

conserved regions, those at the $3^{\prime}$ and $5^{\prime}$ ends (TB1 and TB7) possibly forming stabilization stem-loops. Only the primary sequence of TB3 is conserved, all other structures being supported by covariations. The search for potential mRNA targets yielded significant predictions for fliM (flagellar motor switch) and smc01800 (cytochrome C oxidase). The same sequence of sra32 (nt 60 to 95, TB4 to TB6) is predicted to pair with the 5 ' leader region of both mRNA targets. Discovery of a putative flagella antisense RNA in S. meliloti and related bacteria is interesting. Indeed, all these bacteria interact with plant or mammal cells and flagella are cell-surface components required for eukaryotic-prokaryotic cells interactions [37].

Finally, structure and target prediction of sra41 needed preliminary analysis as (i) two signals were detected by Northern hybridization (a major 106 nt band and a minor $\sim 68 \mathrm{nt}$ species) and (ii) sra41 is present in three imperfect copies, two in tandem in the same chromosomal IGR and the third, with a more divergent primary sequence, maps in pSymA. Additionally, sra 41 is well-conserved in alpha-proteobacteria and is present in two to three copies, on both chromosomes and (mega-)plasmids except in Agrobacterium (chromosomal loci only). Translatable small ORFs are predicted within some sra41 candidates (see Additional file 6) whereas others are devoid of complete coding frames. A similar conserved structure was proposed for the three S. meliloti copies, composed of three stem-loops as described for sra03. Target mRNAs were predicted separately for each of the three sra 41 copies 

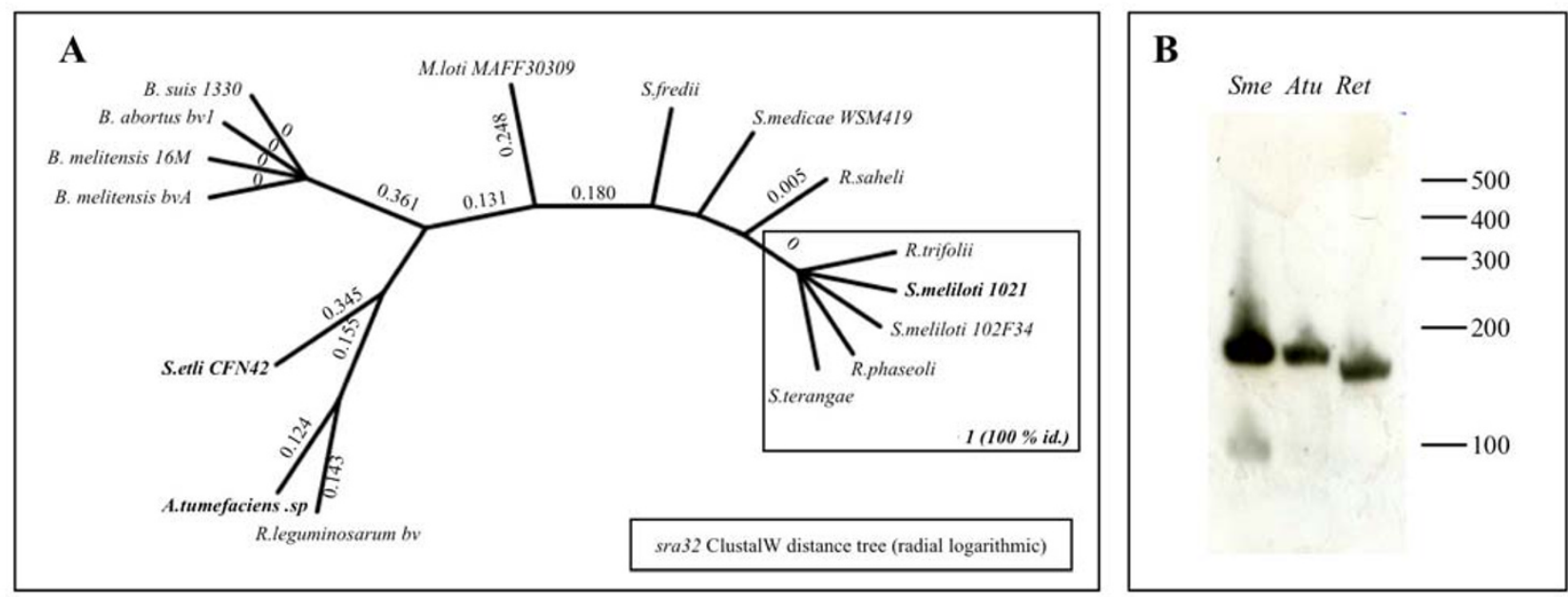

\section{Figure 5}

Characterization of sra32. A. Distance tree of sra32 using the distance/NJ method (clustalW [90]). Numbers at the nodes represent bootstrap proportions (BP) of 1000 replicates. B. In northern blots, a signal for the predicted sra32 was detected corresponding to lengths of I44 and I06 nucleotides in total RNA from S. meliloti I02 I and to I40 and I32 nt in that from Agrobacterium tumefaciens and Rhizobium etli, respectively.

in S. meliloti. The only predicted target for the first chro-

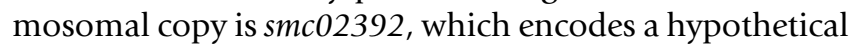
protein with a Sel1 repeat-containing domain. The second copy is predicted to interact with two mRNAs encoding Smc00317, a transmembrane protein with homologies to efflux carrier proteins, and Smc01118, a glucoproteaselike protein possibly involved in chaperoning processes. No significant target was predicted for the pSymA copy.

\section{Conclusion}

We used computational comparative genomic screening to search for small RNA genes in S. meliloti and related alpha-proteobacteria, as very few sRNAs had been identified in this phylum [46]. From a list of $64 \mathrm{~S}$. meliloti candidate IGRs (excluding tmRNA, 4.5S and $r n p B$ ), we show that 17 encode small RNAs (14 non-coding RNAs, two small mRNAs and a $5^{\prime}$ leader region). This work constitutes a significant advance in small RNAs studies in alphaproteobacteria.

A possible antisense function was suggested for $57 \%$ of the sra genes, although these predictions remain based on TargetRNA estimations. To validate these antisense activities, further in vitro validation of predicted target genes will be necessary, even if TargetRNA's e-value was set to a highly significant threshold (see material and methods section). It is however interesting to notice that the functions of the predicted mRNA targets are various, including roles in transport, membranes and toxin-antitoxin systems. However, antisense RNAs may act on transcription termination, translation, mRNA degradation and can be activators and/or repressors. As a consequence, accurate in silico prediction of sra functions is difficult. The specific physiological roles of these newly discovered genes in alpha-proteobacteria regulatory pathways can only be determined by biological investigation. The initial regulation of each sra gene, i.e. the precise signalling conditions that trigger their expression should be analyzed, as this may give us clues about their roles. Monitoring the expression of each sra under various conditions would require numerous experiments, as many parameters can be changed alone or simultaneously to simulate oxidative, heat, cold, and osmotic stresses as well as nutrient and metal starvation. In E. coli, Hfq generally facilitates the pairing of ncRNAs [79]. Therefore the influence of the $S$. meliloti hfq homolog (nrfA or smc01048) in the sra-target mRNAs hybrid formation could be analyzed by constructing a mutant. In parallel, screening should be extended to additional replicons (megaplasmids and plasmids): we show that sequence conservation in closely related bacteria IGRs can indicate the presence of putative small sra genes.

\section{Methods}

\section{Bacterial growth}

In all experiments, S. meliloti strain 1021 (streptomycin resistant, $\mathrm{Str}^{\mathrm{R}}$ ) was grown at $30^{\circ} \mathrm{C}$ in the presence of 25 $\mu \mathrm{g} . \mathrm{ml}^{-1}$ of streptomycin. Bacteria were initially grown to the stationary phase in LB (Luria-Bertani) medium, collected, washed and then resuspended in MV (Vincent 
minimal medium, 1970 [80]) or LB medium. Stresses were applied in MV at mid-exponential phase (OD600 $\mathrm{nm}=0.4)$ as follows: 10 minutes with a sub-lethal dose of hydrogen peroxide (10 mM); salt shock $(0,4 \mathrm{M} \mathrm{NaCl}), \mathrm{pH}$ 5 and $\mathrm{pH} 9$ generated with $10 \mathrm{~N} \mathrm{HCl}$ or $\mathrm{NaOH}$ were also applied during 10 minutes; cold $\left(10^{\circ} \mathrm{C}\right)$ and heat shocks $\left(40^{\circ} \mathrm{C}\right)$ lasted 15 minutes. The other alpha-proteobacteria used in Northern blot and sequencing experiments are listed in Additional file 7.

\section{RNA purification and DNase treatment}

Cells were harvested by centrifugation $(5 \mathrm{~min}, 2600 \times \mathrm{g}$, room temperature) and immediately frozen at $-80^{\circ} \mathrm{C}$. These pellets were subsequently re-suspended in $200 \mu \mathrm{l}$ of TE buffer (10 mM Tris-HCl pH8 - 1 mM EDTA) containing lysozyme (1 mg.ml-1) and total RNA was extracted using the RNeasy ${ }^{\circledR}$ mini kit $\left(\right.$ Qiagen ${ }^{\mathrm{TM}}$ ) and treated with RQ1 Rnase free DNase (1 U. $\mu \mathrm{g}^{-1}, \mathrm{GE}$ Healthcare) in the presence of $6 \mathrm{mM}$ of $\mathrm{MgCl}_{2}$ for $20 \mathrm{~min}$ at $37^{\circ} \mathrm{C}$.

\section{5' and 3' RACE mapping}

RNAs shorter than 300 nt were eluted from a 2.5\% highresolution agarose gel (Sigma) in $0.5 \times$ TBE buffer [81] and used to build a cDNA library using the MessageAmpII-Bacteria kit (Ambion). The RNAs were 3' endpolyadenylated and first strands were synthesized using oligo-T7-dT (AATACGACTCACTATAGGGCGAA dT25) then treated overnight at $37^{\circ} \mathrm{C}$ with terminal deoxynucleotidyl transferase in the presence of $1 \mathrm{mM}$ of dTTP. The second strands were obtained with a 5'-primer (GGAATACTAGTGACACCAGACAAGTTG dA15). PCR was carried out at $55^{\circ} \mathrm{C}$ using $1 \mu$ of the cDNAs and 4 pmoles of the appropriate specific primers (see Additional file 8): one corresponding to the targeted gene and the other specific to either the $5^{\prime}$ or 3 ' tagged ends. The products obtained were inserted into pGEM-T (Promega) and sequenced using the BigDye terminator v3 protocol (Applied Biosystems). RNA genes of interest were amplified by PCR with a $50^{\circ} \mathrm{C}$ to $40^{\circ} \mathrm{C}$ touch-down program, using the $5^{\prime}$ and $3^{\prime}$ end primers designed after mapping, from 12 genomic DNA preparations from several Rhizobia (see Additional file 8). The resulting products were sequenced using the protocol described above and analyzed in silico for co-variation and conserved secondary structure.

\section{Northern dot analysis}

DNase-treated, S. meliloti total RNA (10 $\mu \mathrm{g}$ per dot) was denatured (by incubating for $10 \mathrm{~min}$ at $70^{\circ} \mathrm{C}$ then chilling on ice) and spotted under vacuum onto a nylon membrane (Zeta Probe) using Bio-Dot (Bio-rad). These dot membranes were baked for $30 \mathrm{~min}$ at $80^{\circ} \mathrm{C}$, pre-hybridized, hybridized and washed according to Ambion's instructions (Oligoprobes), and hybridization was visualized on InstantImager (Packard). 20-mer oligonucleotides (see Additional File 3) were 5' P-end labelled with [gamma $\left.{ }^{32} \mathrm{P}\right] \mathrm{ATP}$. For each candidate, two oligonucleotide probes (one per strand) were selected to identify the strand of transcription. Aliquots of 62 pmoles of each oligonucleotide probe were incubated for $1 \mathrm{hr}$ at $37^{\circ} \mathrm{C}$ with $1 \mu \mathrm{l}$ of T4 polynucleotide kinase, $2.5 \mu \mathrm{l}$ of $10 \times$ kinase buffer (Ambion) and $2 \mu \mathrm{l}$ of $32 \mathrm{P}$-ATP $[5,550 \mathrm{KBq}(222,000$ KBq. $\left.\left.\mathrm{mmol}^{-1}\right)\right]$. The radiolabelled probes were then purified through MicroSpin G25 columns (GE Healthcare). The efficiency of probe labelling was monitored in a liquid scintillation analyser (1600 TR Packard).

\section{Northern blot analysis}

$S$. meliloti was grown in LB medium to mid-exponential phase $\left(\mathrm{OD}_{600 \mathrm{~nm}}=0.8\right)$. Total RNA $(10 \mu \mathrm{g})$ was extracted, denatured, and subjected to electrophoresis on an $8 \%$ acrylamide/bis acrylamide (19:1) denaturing gel (8 M urea) in $0.5 \times$ TBE buffer [81]. The RNA was then transferred to a nylon membrane (Ambion) in the same buffer and the membrane was baked for $30 \mathrm{~min}$ at $80^{\circ} \mathrm{C}$. Biotinylated oligoprobes were used for hybridization and bound probes were detected according to Ambion's instructions (BrightStar $^{\circledR}$ BioDetect $^{\mathrm{TM}}$ ).

\section{Construction of the DNA microarrays}

A PCR-based microarray was designed (see Additional file 9) with primer3-designated oligonucleotides derived from the 67 IGRs (intergenic empty regions) identified by screening (see Additional File 4). Seventy bp were excluded at the 5' and 3' ends of each IGR to avoid expression contamination by adjacent genes. The IGRs with lengths >550 nt were amplified as more than one PCR fragment. Each PCR involved $200 \mathrm{ng}$ of S. meliloti 1021 genomic DNA, 1.25 units of TaqDNA polymerase (Promega) and $4 \mathrm{pmol}$ of each oligonucleotide in a final volume of $50 \mathrm{ml}$ for 40 cycles (Peltier Thermal Cycler, MJ Research Inc). The PCR buffer contained $5 \mu \mathrm{MgCl}_{2}(25$ $\mathrm{mM}$ ), $1 \times$ Taq buffer (Promega) and $4.3 \mu \mathrm{l}$ dNTPs. The length and quality of each PCR product was assessed by electrophoresis on 2\% agarose TBE (Tris-Borate EDTA 0.5 $\times$ final) gels. The IGRs-PCR probes were dried, resuspended in $30 \mu$ l betaine, $1.5 \mathrm{M}-3 \times$ SSC and spotted in triplicate onto GAPS $\mathrm{II}^{\mathrm{TM}}$-coated glass slides (Corning) through robotic arraying (Microgrid II, BioRobotics).

\section{Microarray hybridization, data acquisition and statistical analysis}

The labelled cDNA was resuspended in hybridization buffer (3 $\times$ SSC/0.1\% SDS/50\% formamide) and cohybridized with $10 \mu \mathrm{g}$ of salmon sperm DNA to the microarray glass slides overnight at $55^{\circ} \mathrm{C}$. The slides were washed for $5 \mathrm{~min}$ at $55^{\circ} \mathrm{C}$ in wash buffer $(2 \times \mathrm{SSC} / 0.1 \%$ $\mathrm{SDS})$ then $2 \mathrm{~min}$ in high-stringency buffer $(0.2 \times \mathrm{SSC} /$ $0.1 \%$ SDS, twice), 2 min in $0.2 \times$ SSC (twice) and $2 \mathrm{~min}$ in $0.1 \times$ SSC, and dried by centrifugation ( $3 \mathrm{~min}, 210 \mathrm{~g}$ ). 
Hybridized microarray slides were scanned (GenePix4000, Axon Instruments, Inc.) with independent excitation of the fluorophores $\mathrm{Cy} 5$ and $\mathrm{Cy} 3$ at $10-\mu \mathrm{m}$ resolution. Our microarray time series experiment was planned with a dye-swap design; Dabney \& Storey recently showed that a simple average dye-swap removes dye bias without affecting the biological signal and preserves the ordering of true expression means [82]. To determine if ncRNA candidates showed detectable expression as assessed by microarray analysis, we used $\log _{2}$ SNR (signal to noise ratios), the "noise" value being the average intensity of spots containing spotting buffer. All genes with $\log _{2}$ SNR lower than 2 (a signal less than 4 -fold greater than the technological noise) were considered as untranscribed under the conditions tested and their value changed to 0 (filtering). The resulting expression profiles are illustrated as a heat map.

\section{Bioinformatics}

Intergenic regions (IGRs) were determined as genome areas with no gene annotation on either of the two strands. The S. meliloti database used [83] includes original annotations of all ORFs, as well as tRNA, rRNA and repetitive elements. The Artemis Comparison Tool (ACT [84]) from the Sanger Centre [85] was used for whole genome comparisons of IGRs between the S. meliloti chromosome, as the reference, and other alpha-proteobacteria genomes: Agrobacterium tumefaciens strain C58 Cereon, Rhizobium etli CFN42, Rhizobium leguminosarum bv. vicae 3841 and Mesorhizobium loti MAFF303099.

ISI [54] was used taking the initial embl record file corresponding to the $S$. meliloti chromosome (AL591688) as an input, and applying an IGR length threshold of $7 \mathrm{bp}$. Parameter ' $w$ ' in BLAST was set to 7 in order to refine word detection.

In order to produce the input alignment file for QRNA v.2.0.3.c [7], the 61 ncRNAs annotated in the E. coli $\mathrm{K} 12$ Refseq file (NC_000913) were extracted, and compared to the chromosomal IGRs of $S$. meliloti thanks to WU BLAST 2.0, with various e-value thresholds $\left(10^{-5}, 10^{-2}, 0.1\right.$ and default: 10). QRNA was then run with scanning window set to $100 \mathrm{nt}$.

sRNAPredict2 [18] was tested using the S. meliloti chromosome ORF list (NC_003047.ptt) from the Refseq repository [86]. The ".coords" TIGR file is unavailable for $S$. meliloti. The t/rRNA database was compiled from data in the TIGR_CMR RNA list [87] and from the S. meliloti sequencing consortium website [83]. The terminator database was derived from TransTerm [88,89]. The S. meliloti sRNA training set was generated from data available at the corresponding RFAM database page [46]. Two reference genomes were used: Agrobacterium tumefaciens str. C58 and Rhizobium etli CFN 42. Consequently, two blast output files were generated, where $S$. meliloti intergenic regions were compared to the cited genomes using WU BLAST 2.0 with same parameters as Livny [18] $\left(E=10 e^{-5}\right.$, $\mathrm{V}=10000$ et $\mathrm{B}=10000)$. Finally, databases of regions of predicted conserved secondary structure were produced using QRNA, again with parameters set to the same values as in [18]. No input files corresponding to RNAMotif search results or to promoter/transcription binding sites were provided to sRNAPredict.

TargetRNA [61] was used (default parameters) to identify sra candidates' mRNA targets. Potential base pair binding interactions were considered significant only if their $P$ value fell below 0.001. Nucleotide sequences were analyzed by ClustalW [90] and resulting multiple alignments were used in ALIFOLD [71] to model RNA secondary structures. Similar predictions were realized using the RNAz program [72].

\section{Authors' contributions}

$\mathrm{VU}$ and AC conceived the design and use of the microarrays and performed the isolation and blotting of the RNAs. AC performed 5'-3' RACE and sequencing of sra32 candidates in Rhizobiales. ES and FBH performed the bioinformatic analyses and IGRs annotation. FBH designed and coordinated all aspects of the project. All authors read and approved the final manuscript.

\section{Additional material}

\section{Additional file 1}

Phylogenetic maximum likelihood trees of alpha-proteobacteria $\mathrm{ffs}, \mathrm{rnpB}$ and tmRNA sequences. The data provided shows the phylogenetic maximum likelihood trees in subgroup-2 alpha-proteobacteria of the canonical tmRNA, rnpB and ffs small RNAs.

Click here for file

[http://www.biomedcentral.com/content/supplementary/14712164-8-467-S1.pdf]

\section{Additional file 2}

Blast $\mathrm{N}$ detection of $\mathrm{E}$. coli small genes in $\mathrm{S}$. meliloti genome. The data provided describes the results of homology searches for E. coli small RNAs in the $\mathrm{S}$. meliloti genome.

Click here for file

[http://www.biomedcentral.com/content/supplementary/14712164-8-467-S2.pdf]

\section{Additional file 3}

sRNAPredict outputs. The data provided presents the results obtained with sRNAPredict on $\mathrm{S}$. meliloti's chromosome.

Click here for file

[http://www.biomedcentral.com/content/supplementary/14712164-8-467-S3.pdf] 


\section{Additional file 4 \\ Intergenic regions included in this study. The data provided lists the inter- genic regions selected (sra candidates) for in vivo validation and their features. \\ Click here for file \\ [http://www.biomedcentral.com/content/supplementary/1471- \\ 2164-8-467-S4.xls]}

\section{Additional file 5}

Normalized expression levels $\left(\log _{2} S N R\right)$ of IGRs candidates. The data provided compiles the normalized expression levels for the candidates. Click here for file

[http://www.biomedcentral.com/content/supplementary/14712164-8-467-S5.pdf]

\section{Additional file 6}

sra41 multiple loci in $\mathrm{S}$. meliloti and related alpha-proteobacteria. The data provided features the multiple loci of sra41 in subgroup-2 alpha-proteobacteria.

Click here for file

[http://www.biomedcentral.com/content/supplementary/14712164-8-467-S6.pdf]

\section{Additional file 7}

Strains used in this study. The data provided references the different bacteria used in this study.

Click here for file

[http://www.biomedcentral.com/content/supplementary/14712164-8-467-S7.pdf]

\section{Additional file 8}

Oligonucleotides used in RACE and Northern assays. The data provided presents the oligonucleotide sequences used in RACE and Northern assays. Click here for file

[http://www.biomedcentral.com/content/supplementary/1471-

2164-8-467-S8.pdf]

\section{Additional file 9}

Oligonucleotides used in microarray design. The data provided presents the oligonucleotide sequences used in the microarray design.

Click here for file

[http://www.biomedcentral.com/content/supplementary/1471-

2164-8-467-S9.pdf]

\section{Additional file 10}

Short (FASTA) alignment and corresponding synteny results. The data provided shows the results of the search for small regions of homology between alpha-proteobacteria.

Click here for file

[http://www.biomedcentral.com/content/supplementary/1471-

2164-8-467-S10.pdf]

\section{Additional file 11}

Artemis Comparison Tool (ACT) screenshots alignment and corresponding synteny results. The data provided presents the results of the ACT comparisons.

Click here for file

[http://www.biomedcentral.com/content/supplementary/14712164-8-467-S11.pdf]

\section{Additional file 12}

TargetRNA results. The data provided shows the results of the target analysis for each valid sra gene.

Click here for file

[http://www.biomedcentral.com/content/supplementary/14712164-8-467-S12.pdf]

\section{Additional file 13}

Alifold and RNAz secondary predictions. The data provided presents the alternative structures predicted for sra genes depending on the tools used. Click here for file

[http://www.biomedcentral.com/content/supplementary/1471-

2164-8-467-S13.pdf]

\section{Acknowledgements}

Vincent Ulvé and Emeric Sevin were supported by PRIR-ADAPTOME and RdC-PREDATOR Région Bretagne, respectively. This work was supported by the CNRS (Centre National de la Recherche Scientifique) and by the Université Européenne de Bretagne.

\section{References}

I. Eddy SR: Non-coding RNA genes and the modern RNA world. Nature Rev Genet 200I, 2:919.

2. Wassarman KM, Repoila F, Rosenow C, Storz G, Gottesman S: Identification of novel small RNAs using comparative genomics and microarrays. Genes Dev 200I, 13:1637-165I.

3. Olivas WM, Muhlrad D, Parker R: Analysis of the yeast genome: identification of new non-coding and small ORF-containing RNAs. Nucleic Acids Res 1997, 25:4619.

4. Argaman L, Hershberg R, Vogel J, Bejerano G, Wagner EG, Margalit $\mathrm{H}$, Altuvia S: Novel small RNA-encoding genes in the intergenic regions of Escherichia coli. Curr Biol 200I, 2:94I-950.

5. Zago MA, Dennis PP, Omer AD: The expanding world of small RNAs in the hyperthermophilic archaeon Sulfolobus solfataricus. Mol Microbiol 2005, 6:1812-1828.

6. Axmann IM, Kensche P, Vogel J, Kohl S, Herzel H, Hess WR: Identification of cyanobacterial non-coding RNAs by comparative genome analysis. Genome Biol 2005, 9:R73.

7. Chen S, Lesnik EA, Hall TA, Sampath R, Griffey RH, Ecker DJ, Blyn LB: A bioinformatics based approach to discover small RNA genes in the Escherichia coli genome. Biosystems 2002, 23:157- 177 .

8. Klein RJ, Misulovin Z, Eddy S: Noncoding RNA genes identified in AT-rich hyperthermophiles. Proc Natl Acad Sci USA 2002, I I :7542-7547.

9. Schattner P: Searching for RNA genes using base-composition statistics. Nucleic Acids Res 2002, 9:2076-2082.

10. Rivas E, Klein RJ, Jones TA, Eddy SR: Computational identification of noncoding RNAs in $E$. coli by comparative genomics. Curr Biol 200I, 7:1369-I373.

II. Rivas E, Eddy SR: Noncoding RNA gene detection using comparative sequence analysis. BMC Bioinformatics 2001, 2:8.

12. Uzilov AV, Keegan JM, Mathews DH: Detection of non-coding RNAs on the basis of predicted secondary structure formation free energy change. BMC Bioinformatics 2006, 7:173.

13. Babak T, Blencowe BJ, Hughes TR: Considerations in the identification of functional RNA structural elements in genomic alignments. BMC Bioinformatics 2007, 8:33.

14. Rivas E, Eddy SR: Secondary structure alone is generally not statistically significant for the detection of noncoding RNAs. Bioinformatics 2000, 7:583-605.

15. Yachie N, Numata K, Saito R, Kanai A, Tomita M: Prediction of non-coding and antisense RNA genes in Escherichia coli with Gapped Markov Model. Gene 2006, 372:171-18I. 
16. Saetrom P, Sneve R, Kristiansen KI, Snøve O Jr, Grünfeld T, Rognes $T$, Seeberg E: Predicting non-coding RNA genes in Escherichia coli with boosted genetic programming. Nucleic Acids Res 2005 33( I 0):3263-3270.

17. Livny J, Fogel MA, Davis BM, Waldor MK: sRNAPredict: an integrative computational approach to identify sRNAs in bacterial genomes. Nucleic Acids Res 2005, 13:4096-4I05.

18. Livny J, Brencic A, Lory S, Waldor MK: Identification of 17 Pseudomonas aeruginosa sRNAs and prediction of sRNA-encoding genes in 10 diverse pathogens using the bioinformatic tool sRNAPredict2. Nucleic Acids Res 2006, I 2:3484-3493.

19. Vogel J, Bartels V, Tang TH, Churakov G, Slagter-lager JG, Huttenhofer A, Wagner EG: RNomics in Escherichia coli detects new SRNA species and indicates parallel transcriptional output in bacteria. Nucleic Acids Res 2003, 22:6435-6443.

20. Huttenhofer A, Vogel J: Experimental approaches to identify non-coding RNAs. Nucleic Acids Res 2006, 2:635-646.

21. Willkomm DK, Minnerup J, Huttenhofer A, Hartmann RK: Experimental RNomics in Aquifex aeolicus: identification of small non-coding RNAs and the putative 6S RNA homolog. Nucleic Acids Res 2005, 6:1949-1960.

22. Bouche F, Bouche JP: Genetic evidence that DicF, a second division inhibitor encoded by the Escherichia coli dicB operon, is probably RNA. Mol Microbiol 1989, 3:991-994.

23. Wassarman KM, Storz G: 6S RNA regulates E. coli RNA polymerase activity. Cell 2000, I0 I:6 |3-623.

24. Frank DN, Pace NR: Ribonuclease P: unity and diversity in a tRNA processing ribozyme. Annu Rev Biochem 1998, 67:153-180.

25. Moller T, Franch T, Udesen C, Gerdes K, Valentin-Hansen P: Spot 42 RNA mediates discoordinate expression of the $E$. coli galactose operon. Genes Dev 2002, 16:1696-1706.

26. Zwieb C, Gorodkin J, Knudsen B, Burks J, Wower J: tmRDB (tmRNA database). Nucleic Acids Res 2003, 31 :446-447.

27. Rosenblad MA, Gorodkin J, Knudsen B, Zwieb C, Samuelsson T: SRPDB: Signal Recognition Particle Database. Nucleic Acids Res 2003, 31:363-364.

28. Altuvia S, Zhang A, Argaman L, Tiwari A, Storz G: The Escherichia coli OxyS regulatory RNA represses fhIA translationby blocking ribosome binding. EMBO J 1998, 17:6069-6075

29. Majdalani N, Cunning C, Sledjeski D, Elliott T, Gottesman S: DsrA RNA regulates translation of RpoS message by an anti-antisense mechanism, independent of its action as an antisilencer of transcription. Proc Natl Acad Sci USA 1998, 95: $12462-12467$

30. Majdalani N, Hernandez D, Gottesman S: Regulation and mode of action of the second small RNA activator of RpoS translation, RprA. Mol Microbiol 2002, 46:8I3-826.

3I. Lenz DH, Mok KC, Lilley BN, Kulkarni RV, Wingreen NS, Bassler BL: The Small RNA Chaperone Hfq and Multiple Small RNAs Control QuorumSensing in Vibrio harveyi and Vibrio cholerae. Cell 2004, I I 8:69-82.

32. He L, Soderbom F, Wagner EG, Binnie U, Binns N, Masters M: PcnB is required for the rapid degradation of RNAI, the antisense RNA that controls the copy number of ColEI-related plasmids. Mol Microbiol 1993, 9: I I3I-I I 42.

33. Benito Y, Kolb FA, Romby P, Lina G, Etienne J, Vandenesch F: Probing the structure of RNAIII, the Staphylococcus aureus agr regulatory RNA, and identification of the RNA domain involved in repression of protein $\mathbf{A}$ expression. RNA 2000 , 6:668-679

34. Weilbacher T, Suzuki K, Dubey AK, Wang X, Gudapaty S, Morozov I, Baker CS, Georgellis D, Babitzke P, Romeo T: A novel sRNA component of the carbon storage regulatory system of Escherichia coli. Mol Microbiol 2003, 48:657-670.

35. Urbanowski ML, Stauffer LT, Stauffer GV: The gcvB gene encodes a small untranslated RNA involved in expression of the dipeptide and oligopeptide transport systems in Escherichia coli. Mol Microbiol 2003, 37:856-868.

36. Vogel J, Papenfort K: Small non-coding RNAs and the bacterial outer membrane. Curr Opin Microbiol 2006, 9:605-6II.

37. Guillier M, Gottesman S, Storz G: Modulating the outer membrane with small RNAs. Genes Dev 2006, 20:2338-2348.

38. Zhang A, Wassarman KM, Ortega J, Steven AC, Storz G: The Smlike Hfq protein increases OxyS RNA interaction with target mRNAs. Mol Cell 2002 9:1।-22.
39. Shin JH, Price CW: SsrA-SmpB Ribosome Rescue System is Important for Growth of Bacillus subtilis at Low and High Temperatures. J Bacteriol 2007, 189(10):3729-37.

40. Galibert $F$, et al: The composite genome of the legume symbiont Sinorhizobium meliloti. Science 200I, 5530:668-72.

4I. Ulve VM, Cheron A, Trautwetter A, Fontenelle C, Barloy-Hubler F: Characterization and expression patterns of Sinorhizobium meliloti tmRNA (ssrA). FEMS Microbio Lett 2007, 269(1): I I7-123.

42. Brown JW: The ribonuclease $\mathbf{P}$ Database. Nucleic Acids Res 1999 27:314

43. MacLellan SR, Smallbone LA, Sibley CD, Finan TM: The expression of a novel antisense gene mediates incompatibility within the large repABC family of alpha-proteobacterial plasmids. Mol Microbiol 2005, 55(2):6I I-623.

44. Izquierdo J, Venkova-Canova T, Ramirez-Romero MA, Tellez-Sosa J, Hernandez-Lucas I, Sanjuan J, Cevallos MA: An antisense RNA plays a central role in the replication control of a repC plasmid. Plasmid 2005, 3:259-277.

45. Griffiths-Jones S, Moxon S, Marshall M, Khanna A, Eddy SR, Bateman $A$ : Rfam: annotating non-coding RNAs in complete genomes. Nucleic Acids Res 2005, 33:DI2I-D 24.

46. The Rfam Database [http://www.sanger.ac.uk/Software/Rfam/]

47. Corbino KA, Barrick JE, Lim J, Welz R, Tucker BJ, Puskarz I, Mandal M, Rudnick ND, Breaker RR: Evidence for a second class of $\mathbf{S}$ adenosylmethionine riboswitches and other regulatory RNA motifs in alpha-proteobacteria. Genome Biol 2005, 8:R70.

48. Suzuma S, Asari S, Bunai K, Yoshino K, Ando Y, Kakeshita H, Fujita M, Nakamura K, Yamane K: Identification and characterization of novel small RNAs in the aspS-yrvM intergenic region of the Bacillus subtilis genome. Microbiology 2002, I 48:259|-2598.

49. Ando $Y$, Asari S, Suzuma S, Yamane K, Nakamura K: Expression of a small RNA, BS203 RNA, from the yocl-yoc] intergenic region of Bacillus subtilis genome. FEMS Microbiol Lett 2002, 207:29-33.

50. Gohlmann HW, Weiner J, Schon A, Herrmann R: Identification of a small RNA within the pdh gene cluster of Mycoplasmo pneumoniae and Mycoplasma genitalium. I Bacteriol 2000, 182:328I-3284.

51. Pichon C, Felden B: Small RNA genes expressed from Staphylococcus aureus genomic and pathogenicity islands with specific expression among pathogenic strains. Proc Natl Acad Sci USA 2005, 102:14249-14254

52. Axmann IM, Kensche P, Vogel J, Kohl S, Herze H, Hess WR: Identification of cyanobacterial non-coding RNAs by comparative genome analysis. Genome Biol 2005, 6:R73.

53. Trotochaud $A E$, Wassarman KM: A highly conserved 6S RNA structure is required for regulation of transcription. Nat Struct Mol Biol 2005, 12:313-319.

54. Pichon C, Felden B: Intergenic sequence inspector: searching and identifying bacterial RNAs. Bioinformatics 19(13):1707-9. 2003, Sep I

55. Osteras M, Stanley J, Finan TM: Identification of Rhizobium-specific intergenic mosaic elements within an essential twocomponent regulatory system of Rhizobium species. J Bacteriol 1995, I77:5485-5494

56. Osteras M, Boncompagni E, Vincent N, Poggi MC, Le Rudulier D Presence of a gene encoding choline sulfatase in Sinorhizobium meliloti bet operon: choline-O-sulfate is metabolized into glycine betaine. Proc Natl Acad Sci USA 1998, 95: I I394-I I 399.

57. Sullivan JT, Ronson CW: Evolution of rhizobia by acquisition of a 500-kb symbiosis island that integrates into a phe-tRNA gene. Proc Natl Acad Sci USA 1998, 9:5 |45-5 I49. Erratum in: Proc. Natl. Acad. Sci. USA I 5:9059

58. Zengel JM, Lindahl L: Diverse mechanisms for regulating ribosomal protein synthesis in Escherichia coli. Prog Nucleic Acid Res Mol Biol 1994, 47:33I-370.

59. Benard L, Philippe C, Ehresmann B, Ehresmann C, Portier C: Pseudoknot and translational control in the expression of the SI5 ribosomal protein. Biochimie 1996, 78:568-576.

60. Mantri Y, Williams KP: Islander: a database of integrative islands in prokaryotic genomes, the associated integrases and their DNA site specificities. Nucleic Acids Res 2004:D55-8.

61. Tjaden B, Goodwin SS, Opdyke JA, Guillier M, Fu DX, Gottesman S, Storz G: Target prediction for small, noncoding RNAs in bacteria. Nucleic Acids Res 2006, 34:279|-2802. 
62. Wiggerich HG, Klauke B, Koplin R, Priefer UB, Puhler A: Unusual structure of the ton $B$-exb DNA region of Xanthomonas campestris pv. campestris: ton $B$, exbB, and exbDI are essential for ferric iron uptake, but exbD2 is not. J Bacteriol 1997, I79:7103-7|10.

63. Jacques JF, Jang S, Prevost K, Desnoyers G, Desmarais M, Imlay J, Masse E: RyhB small RNA modulates the free intracellular iron pool and is essential for normal growth during iron limitation in Escherichia coli. Mol Microbiol 2006, 62: I I8I-I I 90.

64. Hershberg R, Altuvia $\mathrm{S}$, Margalit $\mathrm{H}$ : A survey of small RNA-encoding genes in Escherichia coli. Nucleic Acids Res 2003, 31:1813-20.

65. Karzai AW, Susskind MM, Sauer RT: SmpB, a unique RNA-binding protein essential for the peptide-tagging activity of SsrA (tmRNA). EMBO J 1999, 18:3793-3799.

66. MacLellan SR, Smallbone LA, Sibley CD, Finan TM: The expression of a novel antisense gene mediates incompatibility within the large repABC family of alpha-proteobacterial plasmids. Mol Microbiol 2005, 55:6 I I-623.

67. Dombrecht B, Marchal K, Vanderleyden J, Michiels J: Prediction and overview of the RpoN-regulon in closely related species of the Rhizobiales. Genome Biol 2002, 3(I2):

68. Okumura T, Makiguchi H, Makita Y, Yamashita R, Nakai K: Melina II: a web tool for comparisons among several predictive algorithms to find potential motifs from promoter regions. Nucleic Acids Res 2007, 35:W227-23I

69. Unniraman S, Prakash R, Nagaraja V: Conserved economics of transcription termination in eubacteria. Nucleic Acids Res 2002, 30:675-684.

70. Hofacker IL: Vienna RNA secondary structure server. Nucleic Acids Res 2003, 31:3429-3431.

71. A Web Interface for the Prediction Consensus Structures of Aligned Sequences [http://rna.tbi.univie.ac.at/cgi-bin/alifold.cgi]

72. Gruber AR, Neubock R, Hofacker IL, Washietl S: The RNAz web server: prediction of thermodynamically stable and evolutionarily conserved RNA structures. Nucleic Acids Res 2007, 35:W335-338.

73. Nakamura K, Miyamoto H, Suzuma S, Sakamoto T, Kawai G, Yamane K: Minimal functional structure of Escherichia coli 4.5 S RNA required for binding to elongation factor $\mathbf{G}$. J Biol Chem 200I, 276:22844-22849.

74. Barrick JE, Sudarsan N, Weinberg Z, Ruzzo WL, Breaker RR: 6S RNA is a widespread regulator of eubacterial RNA polymerase that resembles an open promoter. RNA 2005, 5:774-784.

75. Small E, Marrington R, Rodger A, Scott DJ, Sloan K, Roper D, Dafforn TR, Addinall SG: FtsZ polymer-bundling by the Escherichia coli ZapA orthologue, YgfE, involves a conformational change in bound GTP. J Mol Biol 2007, 369:210-22I.

76. Kihara A, Akiyama $Y$, Ito $K$ : Host regulation of lysogenic decision in bacteriophage lambda: transmembrane modulation of FtsH (HflB), the cll degrading protease, by HflKC (HflA). Proc Natl Acad Sci USA 1997, 94:5544-5549.

77. Gerdes K, Wagner EG: RNA antitoxins. Curr Opin Microbiol 2007, 10:117-124.

78. Sevin EW, Barloy-Hubler F: RASTA-Bacteria: a web-based tool for identifying toxin-antitoxin loci in prokaryotes. Genome Biol 2007, 8:RI55.

79. Aiba $\mathrm{H}$ : Mechanism of RNA silencing by Hfq-binding small RNAs. Curr Opin Microbiol 2007, 10:134-139.

80. Vincent JM: A manual for the practical study of root-nodule bacteria. Blackwell Scientific Publications, Oxford; 1970.

81. Sambrook J, Fritsch EF, Maniatis T: Molecular cloning. 2nd edition. New York: Cold Spring Harbor Laboratory Press; 1989.

82. Dabney AR, Storey JD: A new approach to intensity-dependent normalization of two-channel microarrays. Biostatistics 2007, 8(I): $128-139$

83. The Sinorhizobium meliloti strain 1021 Genome Project [http://bioinfo.genopole-toulouse.prd.fr/annotation/iANT/bacteria/ rhime/index.html]

84. Carver TJ, Rutherford KM, Berriman M, Rajandream MA, Barrell BG Parkhill J: ACT: the Artemis Comparison Tool. Bioinformatics 2005, $21: 3422-3$.

85. The Artemis Comparison Tool [http://www.sanger.ac.uk/Soft ware/ACT]

86. The Refseq Database [ftp://ftp.ncbi.nih.gov/genomes/Bacteria/]
87. The Comprehensive Microbial Resource [http:pathema.tigr.org/tigr-scripts/CMR/shared/Make FrontPages.cgi?.page $=$ rna list

88. Jacobs GH, Stockwell PA, Tate WP, Brown CM: Transterm extended search facilities and improved integration with other databases. Nucleic Acids Res 2006, 34:D37-40.

89. The Database of mRNA related information [http:// www.genomics.jhu.edu/TransTerm/transterm.html]

90. Higgins D, Thompson J, Gibson T, Thompson JD, Higgins DG, Gibson TJ: CLUSTAL W: improving the sensitivity of progressive multiple sequence alignment through sequence weighting, position-specific gap penalties and weight matrix choice. Nucleic Acids Res 1994, 22:4673-4680.
Publish with Bio Med Central and every scientist can read your work free of charge

"BioMed Central will be the most significant development for disseminating the results of biomedical research in our lifetime. "

Sir Paul Nurse, Cancer Research UK

Your research papers will be:

- available free of charge to the entire biomedical community

- peer reviewed and published immediately upon acceptance

- cited in PubMed and archived on PubMed Central

- yours - you keep the copyright 